\title{
Business Education and Training During the Enterprises' Digital Transformation: Notation Alignment and Equivalence Rules Among the Enterprises' Business Process Models
}

\author{
Athanasios G. Lazaropoulos ${ }^{1,2}$ \\ ${ }^{1}$ School of Electrical and Computer Engineering, National Technical University of Athens, 9 Iroon Polytechniou Street, Zografou, GR \\ 15780, Greece \\ ${ }^{2}$ Public Power Corporation S. A., IT Department, 190-194 Mesogeion Avenue, Cholargos, GR 15561, Greece \\ E-mail: AGLazaropoulos@gmail.com
}

Received: 3 January 2021; Revised: 22 March 2021; Accepted: 22 March 2021

\begin{abstract}
Business process modeling attracts great importance in enterprises due to the need for a graphically simplified and less verbal way to manage their operations. Nevertheless, the existence of various process modeling standards across the different departments of the same enterprise, such as Business Process Modeling Notation (BPMN) diagrams, classic flowcharts, Gantt charts and Petri nets, urges their notation alignment. After the business process model notation alignment, complex constraints and relationships among the enterprise's department processes can be automated and simplified. In the light of the digital transformation of today's enterprises, the main objective of this paper is the proposal of a straightforward and simplified business educational equivalence table so that a direct conversion among BPMN diagrams, flowcharts, Gantt Charts and Petri Nets can be locally fulfilled by non-specialized personnel in each enterprise's department. The methodology of this paper can be generalized in every enterprise where the aforementioned process modeling standards across its different departments coexist.
\end{abstract}

Keywords: business process modeling standards, BPMN diagrams, classic flowcharts, Gantt charts, Petri nets, digital transformation, project management, total quality management (TQM), business analytics

JEL Codes: C44, L15, M11, M15, O22, O32

\section{Introduction}

In the light of the digital transformation of enterprises, a clear need for meticulously describing their business processes and workflows in an expressive, formal but yet understandable language in a less verbal way by final users and not only by specialized personnel faced out (Chinosi \& Trombetta, 2012). Although the state-of-art language for modeling business processes and workflows is nowadays the Business Process Model and Notation (BPMN) standard with its diagrams, the different departments of the same enterprise may retain the knowledge concerning their business processes and workflows on older or more complicated process modeling standard diagrams, such as classic flowcharts, Gantt charts and Petri nets (Draheim, 2010). Therefore, keeping up with the times, the primary objective should be the

Copyright (C2021 Athanasios G. Lazaropoulos.

DOI: https://doi.org/10.37256/redr.212021764

This is an open-access article distributed under a CC BY license

(Creative Commons Attribution 4.0 International License)

https://creativecommons.org/licenses/by/4.0/ 
conversion of all the existing process modeling standard diagrams into the respective BMPN ones so that they can be examined and assessed as a whole by the enterprise's stakeholders and digital transformation experts. The secondary objective of the business process model notation alignment remains the possibility of conversion from any to any process modeling standard diagram so that the diagrams can be quickly studied, understood and reused by the nonspecialized personnel of the different enterprise's departments (Aldin \& Cesare, 2011). To fulfill both the aforementioned objectives, a straightforward and simplified business educational equivalence table that will match each element of each process modeling standard diagram with respective elements in the remaining process modeling standard diagrams is proposed in this paper after collecting all the available elements of the existing process modeling standard diagrams of all the enterprise's departments. It should be noted that the proposed equivalence table is not intended to report all the theoretically possible conversions among the elements of the aforementioned four process modeling standard diagrams but to practically demonstrate the conversions of the most used and yet applied elements in enterprises on the basis of BMPN standard diagrams so that the non-specialized personnel of the enterprises' departments can perform the required conversions after a fast-track business training program.

So far, a plethora of works in the literature has been devoted to the study of the process modeling standards of interest in this paper, say, BPMN diagrams, classic flowcharts, Gantt charts and Petri nets, as well as the conversion among their elements. As the BPMN standard is concerned, which is anyway the state-of-art business process modeling standard in enterprises and is treated as the basis standard in this paper, BPMN standard provides graphical notations and diagrams for detailing business processes and workflows. BPMN version 2, which is the latest version and adopted in this paper, has been developed and maintained by the Object Management Group (OMG) and is widely accepted by enterprises due to its visual language in a less verbal way that can be understood without misinterpretations (Object Management Group, 2011; White, 2004a; Simpson, 2004). The main strengths of BPMN diagrams are their high degree of expression (say, variety of described scenarios), the connectivity at different levels, readability, integration with Enterprise Resource Planning (ERP) systems and their diagram creation/maintenance by non-specialized personnel due to its flowcharting technique (Grigorova \& Mironov, 2014). As the classic flowcharts are concerned, these are the first structured methods for documenting process flows (Gilbreth \& Gilbreth, 1921) and remain very popular to the nonspecialized personnel due to the simplicity of their common symbols. But the classic flowcharts are nowadays used as teaching tools since their descendant modeling standards, such as BPMN, are designed to become more accurate and suitable for describing business processes and workflows in terms of the market perspective, interfaces with databases and model-retaining execution (Pucher, 2012). As the Gantt charts are regarded, their main purpose is to illustrate the time schedule and the dependencies among business processes (Kumar, 2005; Burkhard et al., 2005; Geraldi \& Lechter, 2012). Gantt charts mainly focus on the presentation of the current schedule status by exploiting start and finish dates of the business processes rather than revealing the inner workflows and the exact input/output details of the connected business processes. Similarly to BPMN standard, Petri nets offer a graphical notation for stepwise business processes that include duration, choice and concurrent execution (Maung \& Hein, 2014). In contrast with BPMN standard, Petri nets can be treated rather as a mathematical formality for process analysis than a digital transformation tool by the enterprise's stakeholders since the creation and maintenance of Petri nets demand special programming and mathematical knowledge by the involved personnel (Van der Aalst, 1998; Murata, 1989). Anyway, despite their differences and strong/weak characteristics and since there was no standardization for modeling business processes and workflows in many enterprises so far, all the aforementioned process modeling standards are able to describe the business processes and workflows and for that reason all the four standards have been applied to the documentation of the various enterprises' departments in different extents. In the light of the digital transformation of enterprises and the required notation alignment and equivalence rules among the four process modeling standards, the proposed straightforward and simplified business educational equivalence table is based on the already established knowledge in the field of conversions among the four process modeling standards (say, between BPMN diagrams and classic flowcharts (Kelemen et al., 2013; Sarab et al., 2020; Cahyani et al., 2020), between BPMN diagrams and Gantt Charts (Flores \& Sepúlveda, 2010), between BPMN diagrams and Petri Nets (El Hichami et al., 2014; Awad, 2013; Dijkman et al., 2008), between classic flowcharts and Petri Nets (Draheim, 2010), and between Gantt Charts and Petri Nets (Wu et al., 2019)). The methodology and the results of this paper can be generalized in any enterprise that may support a variety of the aforementioned process modeling standards across its different departments.

The rest of this paper is organized as follows: Section 2 briefly presents the four process modeling standards of 
this paper, say, BPMN diagrams, classic flowcharts, Gantt charts and Petri nets as well as their popular basic elements that are present in the documentation of the enterprises' departments. In this Section, the proposed business educational equivalence table among the aforementioned process modeling standards is first demonstrated on the basis of their basic elements. In Section 3, the straightforward conversion results of a real business workflow are demonstrated in all the four process modeling standards by exploiting the proposed business educational equivalence table. Section 4 concludes this work.

\section{The four process modeling standards and the business educational equivalence table}

In this Section, a brief synopsis of the four process modeling standards of interest, say, BPMN diagrams, classic flowcharts, Gantt charts and Petri nets, is presented in respective subsections. For each process modeling standard, its basic elements, which are used in the documentation of the power utility's departments, are demonstrated and analyzed while the applied software for the graphical representation of the diagrams is suggested in each case. This Section concludes with the proposal of the business educational equivalence table where the correspondence of the basic elements of the four process modeling standards is analytically presented.

\subsection{BPMN}

In accordance with Chinosi \& Trombetta (2012), Object Management Group (2011), Allweyer (2016) and Wohed et al. (2006), BPMN standard aims at specifying business process diagrams that can quickly describe complex business processes and, at the same time, remain easily understandable by non-specialized personnel. Also, due to their flowchart nature, BPMN diagrams can be mapped to business execution languages and be further integrated with ERP systems.

According to White (2004b), a BPMN diagram consists of basic elements that can be further divided into four categories of elements; say, flow objects, connecting objects, swimlanes and artifacts. In Table 1, the four categories of elements are reported as well as their respective basic elements that come from the documentation of the enterprise's business processes. Note that for each basic element of Table 1, its symbol is given as well as a brief description of its functionality.

From Table 1, it is evident that additional variation and information can be added by incorporating internal markers in the already rich portfolio of BPMN diagram basic elements in order to serve higher complexities without disrupting the simplicity and understandability of the BPMN diagrams. Anyway, different levels of precision can be supported through the description of the Activities applied in the BPMN diagram.

As the graphical implementation of the BPMN diagrams is concerned, Microsoft Visio 2016 is going to be used in this paper since Microsoft Visio 2016 supports BPMN version 2 and corresponding BPMN diagram validation rules that will allow the visual correctness of BPMN diagrams in terms of the rules specified in the BPMN standard (Microsoft, 2012).

\subsection{Classic flowcharts}

Classic flowcharts can be considered as diagrammatic representations of algorithms and are especially applied in computer science courses in every level of the educational pathway and, for the last reason, classic flowcharts are very familiar to the non-specialized personnel. As a generic process model, classic flowcharts have been extensively used to analyze, design, document and manage business processes in various enterprises.

Similarly to BPMN standard, a classic flowchart consists of basic elements that can be informally divided into the same element categories of BPMN; say, flow objects, connecting objects, swimlanes and artifacts. Note that a lot of efforts have been made since 1960s in order to set standards for the basic elements of the classic flowcharts and during these years many basic symbols have been added to describe process in various fields (Shelly \& Vermaat, 2013; Myler, 1998; ISO, 1985; IBM, 1969). In Table 2, the basic elements of the classic flowcharts, which are reported in Shelly \& Vermaat (2013), Myler (1998) and are suitable for the business process modeling, are divided into the same four categories of BPMN elements for the sake of this paper analysis. Also, in Table 2, the symbol and the brief description 
of the functionality are given for each of the basic elements of the classic flowcharts.

Table 1. Basic elements and their categories in BPMN diagrams (White, 2004b)

\begin{tabular}{|c|c|c|c|}
\hline $\begin{array}{l}\text { Category of } \\
\text { Elements }\end{array}$ & $\begin{array}{l}\text { Basic Element } \\
\text { Name }\end{array}$ & Basic Element Symbol & Basic Element Functionality Description \\
\hline \multirow{4}{*}{ Flow Objects } & Event & & $\begin{array}{l}\text { At the first row, from the left symbol to the right one, the three types of Events are } \\
\text { Start, Intermediate and End, respectively. Internal markers (i.e., cause or impact) } \\
\text { may further specialize the use of the Event symbols } \\
\text { At the second row, from the left symbol to the right one, three examples of } \\
\text { specialized Events that are used in the enterprise's documentation are the Message } \\
\text { Trigger, the Timer Trigger and the Business Rule, respectively }\end{array}$ \\
\hline & $\begin{array}{c}\text { Message } \\
\text { Event }\end{array}$ & & $\begin{array}{l}\text { From the left symbol to the right one, the two specialized Event symbols of } \\
\text { sending and receiving messages are given, respectively }\end{array}$ \\
\hline & Activity & & $\begin{array}{l}\text { The generic Activity is used to describe the work that is performed by the } \\
\text { department (or subdepartment) and can be differentiated by the applied internal } \\
\text { markers }\end{array}$ \\
\hline & Gateway & & $\begin{array}{l}\text { Depending on their internal markers, Gateways represent the decisions that need } \\
\text { to be taken thus controlling the Sequence Flow lines (see below) through forking, } \\
\text { merging and joining. Internal markers may further specialize the use of the } \\
\text { Gateway symbol of first row } \\
\text { At the second row, from the left symbol to the right one, three examples of } \\
\text { specialized Gateways that are used in the enterprise's documentation are the } \\
\text { Parallel Flow, the Exclusive Flow and the Event-Based Flow, respectively }\end{array}$ \\
\hline \multirow{3}{*}{ Swimlanes } & Pool & & Pools organize and categorize Activities of an enterprise's department \\
\hline & Lane & & $\begin{array}{l}\text { Lanes that are sub-partition within a Pool organize and categorize Activities of a } \\
\text { subdepartment }\end{array}$ \\
\hline & Data Object & & Data that are required or produced by activities \\
\hline \multirow{4}{*}{ Artifacts } & Database & & Databases where data are stored \\
\hline & Group & & It is used for documentation or analysis purposes by grouping elements \\
\hline & $\begin{array}{c}\text { Text } \\
\text { Annotation }\end{array}$ & & $\begin{array}{l}\text { Text Annotation (comments) for the business analysts and non-specialized } \\
\text { personnel }\end{array}$ \\
\hline & $\begin{array}{l}\text { Sequence } \\
\text { Flow Line }\end{array}$ & & Sequence Flow lines are used to show the Activity order in the business process \\
\hline \multirow[t]{2}{*}{$\begin{array}{l}\text { Connecting } \\
\text { Objects }\end{array}$} & $\begin{array}{l}\text { Message Flow } \\
\text { Line }\end{array}$ & $a$ & Message Flow lines are used to show the message exchange \\
\hline & $\begin{array}{l}\text { Association } \\
\text { Line }\end{array}$ & & $\begin{array}{l}\text { Association lines are used to associate Data Objects and Text Annotations with the } \\
\text { basic elements of the Flow Object category }\end{array}$ \\
\hline
\end{tabular}

By comparing Tables 1 and 2, similarities and differences between BPMN diagrams and classic flowcharts can be pointed out. As the basic elements of the classic flowcharts are concerned, these elements present great similarities 
with the ones of the BPMN diagrams both as symbols and as functionalities (e.g., Processes, Data Files, etc). The main differences of the classic flowcharts against the BPMN diagrams are primary their workflow (i.e., classic flowcharts generally flow from top to bottom (IBM, 1969), observe the orientation of Pool and Lane symbols) and secondarily the flowlines; only one type of flowlines exists in classic flowchart in contrast with the three flow line types of BPMN diagrams. Anyway, the four categories of elements of BPMN diagrams can conveniently be preserved in classic flowcharts.

As the graphical implementation of the classic flowcharts is concerned, Microsoft Visio 2016 is going to be used in this paper since Microsoft Visio 2016 supports the design of classic flowcharts as well as their light extension to crossfunctional flowcharts (Microsoft, n.d.). Similarly to BPMN diagrams, Microsoft Vision 2016 supports validation rules for the classic flowcharts in terms of the rules specified for the preparation of the classic flowcharts.

Table 2. Basic elements of the classic flowcharts (grouped in the categories of BPMN diagrams) (Shelly \& Vermaat, 2013; Myler, 1998; IBM, 1969)

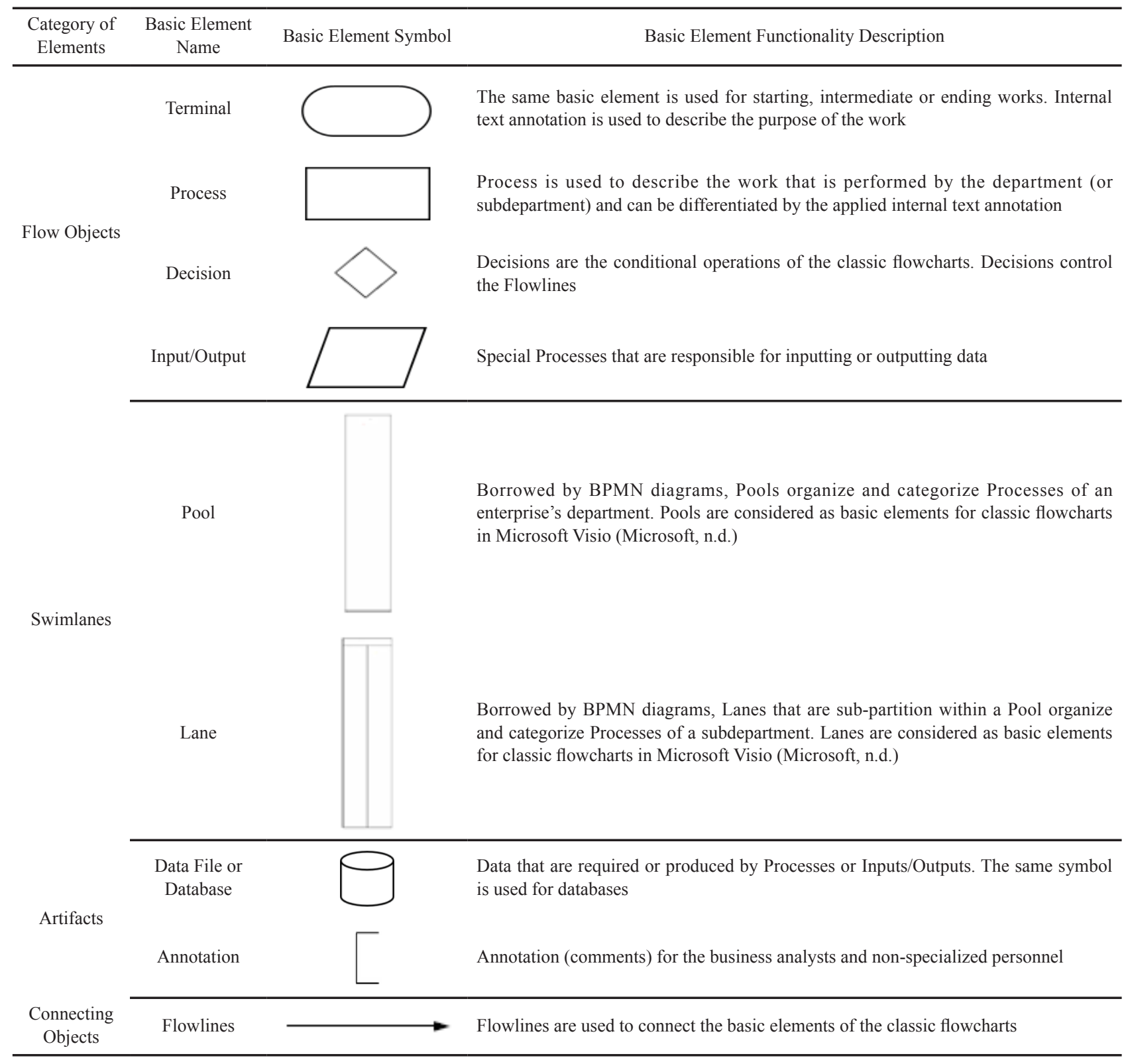




\subsection{Gantt charts}

Gantt charts are among the oldest techniques available for sequencing and scheduling processes (Ben-Daya et al., 2009). Gantt charts are bar charts that focus on the start/finish times of the activities of a process as well as their dependencies. Similarly to BMPN diagrams, the flow of Gantt charts is from the left to the right while the basic elements of Gantt charts are focused on the activities and their flows (Pathak, 2015; Lee \& Shvetsova, 2019). Conversely to BPMN diagrams, Gantt charts are mainly interested in the time durations of the tasks of the processes.

Similarly to BPMN diagrams and classic flowcharts, the basic elements of Gantt Charts, which are reported in (Flores \& Sepúlveda, 2010; Wu et al., 2019; Ben-Daya et al., 2009; Pathak, 2015) and are suitable for the business process modeling, are divided into two categories of BPMN elements, as done in the case of classic flowcharts, and reported in Table 3. Also, in Table 3, the symbol and the brief description of the functionality are given for each of the basic elements of the Gantt charts.

Table 3. Basic elements of the Gantt charts (grouped in the categories of BPMN diagrams) (Flores \& Sepúlveda, 2010; Wu et al., 2019; Ben-Daya et al., 2009; Pathak, 2015)

\begin{tabular}{ccc}
$\begin{array}{c}\text { Category of } \\
\text { Elements }\end{array}$ & $\begin{array}{c}\text { Basic Element } \\
\text { Name }\end{array}$ & Basic Element Symbol \\
\hline Flow Objects & Task & $\begin{array}{l}\text { Similarly to the Terminal symbol of the classic flowcharts, the same basic } \\
\text { element of Milestone is used for starting or ending works. Also, other } \\
\text { intermediate important dates of the process can be indicated }\end{array}$ \\
Connecting & Link lines & $\begin{array}{l}\text { Task is used to describe the work that is performed in the process and is similar } \\
\text { to Activity of BPMN diagrams and Process of classic flowcharts. The length of } \\
\text { the Task symbol depends on the length of the work }\end{array}$ \\
\hline
\end{tabular}

From Table 3, it is evident that Gantt charts are more suitable for project scheduling and control rather than business process modeling due to the lack of basic elements and their focus is on the time management. Due to the requirements of this paper concerning the business process modeling, the critical path and the slacks, which are basic elements during the preparation and study of the Gantt charts, are omitted in Table 3 and are outside the scope of this paper.

By comparing Table 3 with Tables 1 and 2, there is an essential lack of basic elements in the categories of Swimlanes and Artifacts that entails difficulties in: (i) the task allocation among the departments and the subdepartments, which are involved in the described process; and (ii) the conditional operation. To be notationally aligned the BPMN diagrams and classic flowcharts with Gantt charts due to the Gantt chart time requirements, the internal markers of the BPMN diagram Activities and the internal text annotations of classic flowchart Processes should consider the durations of the described works. As the graphical implementation of the Gantt charts is concerned, Microsoft Visio 2016 is going to be used in this paper.

\subsection{Petri nets}

Petri nets can be considered as a mathematical tool for modeling, analyzing, simulating, rapid prototyping and verifying dynamic systems with concurrent and non-deterministic behavior such as the business processes (Rajabi \& Lee, 2009; Bauskar \& Mikolajczak, 2006). In fact, Petri nets can be applied as the formal language to verify BPMN diagrams and classic flowcharts due to their mathematical formulation and simulation capabilities. However, the application of Petri Nets for business process modeling may lead to complex bipartite-directed graphs and corresponding net models that require respective specialized mathematical and programming knowledge for the involved personnel to be handled with. 
Similarly to BPMN diagrams, classic flowcharts and Gantt charts, the basic elements of Petri Nets, which are reported in (Maung \& Hein, 2014; Mutarraf et al., 2018; Rajabi \& Lee, 2009), are divided into two categories of BPMN elements, as done in the case of classic flowcharts and Gantt charts, and reported in Table 4. Also, in Table 4, the symbol and the brief description of the functionality are given for each of the basic elements of the Petri Nets.

From Table 4, it is evident that the business process modeling of Petri nets is concentrated on the token game rather than on the Activities and their flows. The nature of basic elements of Petri nets is different from the nature of the basic elements of the aforementioned graphical representations since the main interest of Petri nets is to be transformed into mathematical network equations and corresponding simulations. In fact, Petri nets can be considered as a simulation tool for the aforementioned graphical representations and are more useful as dynamic simulations and not as static diagrams. Also, to be notationally aligned the BPMN diagrams and classic flowcharts with Petri nets due to their time requirements, the internal markers of the BPMN diagram Activities and the internal text annotations of classic flowchart Processes should consider the durations of the described works as done in Gantt Charts. In accordance with (Awad, 2013; Mutarraf et al., 2018), combinations of the flow object category basic elements of Petri nets should be considered in the proposed straightforward and simplified business educational equivalence table so that the aforementioned combinations can similarly behave to the basic elements of the BPMN diagrams, classic flowcharts and Gantt charts and Petri nets can decently operate as business process modeling technique. Note that Gantt Charts and Petri Nets present similarities since they can be considered more suitable for the project scheduling and control rather than business process modeling. For the previous reason, the Token symbol is outside the scope of this paper since static graphical representations of business process models are of interest rather than the animated dynamic simulations of the project scheduling and controlling. As the static graphical implementations of the Petri nets are concerned, Microsoft Visio 2016 is used while HPetriSim can be optionally used as Petri net simulator and for validation reasons (Anschuetz, 2018).

Table 4. Basic elements of the petri nets (grouped in the categories of BPMN diagrams) (Maung \& Hein, 2014; Mutarraf et al., 2018; Rajabi \& Lee, 2009)

\begin{tabular}{lcl}
$\begin{array}{c}\text { Category of } \\
\text { Elements }\end{array}$ & $\begin{array}{c}\text { Basic Element } \\
\text { Name }\end{array}$ & Place \\
\hline Flow Objects & Transition & $\begin{array}{l}\text { Places are treated as the prerequisites of an Activity and can contain Tokens (see } \\
\text { below). } \\
\text { Transitions determine whether all the preconditions for the Activity are } \\
\text { fulfilled. When transitions fire, they remove tokens from their input places and } \\
\text { add tokens at all of their output places }\end{array}$ \\
Tobjects & Arcs & Arcs connect Place to Transition or Transition to Place
\end{tabular}

\subsection{The simplified business educational equivalence table}

Since the primary objective of this paper is the conversion of all the existing process modeling standard diagrams into the respective BMPN ones, BPMN standard will act as the basis standard and for that reason the first three columns of Table 1 are used as the first three columns of the simplified business educational equivalence table that is shown in Table 5. On the basis of the definitions given in Tables 2-4 for each basic element of the classic flowcharts, Gantt charts and Petri nets and the existing enterprise documentation in business process models, the fourth, fifth and sixth columns of Table 5 present in black color the equivalent basic element symbols of the classic flowcharts, Gantt charts and Petri nets, respectively, for each BPMN diagram basic element. In order to expand the notation alignment and the equivalence rules among the business process models of this paper, the basic elements of the BPMN diagram are enriched with symbols in red color so that the more specialized basic symbols of the classic flowcharts, Gantt charts and Petri nets can have one-to-one correspondences (e.g., the Input/Output symbol of the classic flowcharts). Similar small modifications, 
which are added in red color, are made in the basic symbols of the classic flowcharts, Gantt charts and Petri nets so that an one-to-one correspondence among the basic symbols of the business process models of this paper can be established. The last column characterize each conversion case with its unique identity number.

By observing Table 5 and its 24 proposed conversion cases, several interesting observations can be pointed out concerning the notation alignment and the equivalence rules among the enterprise's business process models, namely:

1. Apart from being the state-of-art business process model, BPMN is characterized by a great number of basic symbols that are able to describe a plethora of different situations during the enterprise's life. In fact, the only modifications made in the BPMN basic symbols are (i) the Input/Output Activity; and (ii) the time requirements added in the Activity descriptions. Note that the time requirements added in the Activity descriptions have been made so that the notation alignment and the equivalence rules between BPMN diagrams and Gantt charts may be feasible.

2. During the processes, a lot of decisions should be made by the involved personnel and stakeholders. By analyzing the nature of the aforementioned decisions, the generic BPMN symbol of Gateway is proven to be relatively fuzzy and for that reason five variations of the generic BPMN symbol of Gateway are applied. Due to the richness of the BPMN basic symbol portfolio, there is no need for proposing new symbols but to pick the right specialized Gateway symbol supported by BPMN.

3. As the classic flowchart basic element symbol portfolio is concerned, its simplicity and intuitive understandability remains at the same time the main disadvantage of this business process model. Only for the Terminal symbol, six modifications are required so that an one-to-one correspondence with the BPMN Event symbols can be established. Also, several modifications are required for the Classic Flowchart Decision Gateway by taking into account that the Decision symbol of the classic flowcharts requires two output Flowlines. Similarly to BPMN, time requirements are added in the Process descriptions of the Classic Flowchart so that the notation alignment and the equivalence rules between Gantt charts and Petri nets can be sustained. Finally, the lack of different types of Flowlines in the case of the classic flowcharts urges their modifications when message flow lines and association lines need to be represented.

4. In the case of Gantt Charts, a lot of modifications have been adopted in the few basic symbols so that Gantt charts can be considered to be an equal business process model to the existing BPMN and classic flowchart ones. Indeed, 6 Milestone symbols have been redesigned so that all the Events can be represented. Same need for enrichment occurs in the case of Tasks and Link lines. But the most challenging issue remains the representation of Gateway conditions and produced Artifacts; here, the involved Tasks should explain verbally the situations in each case since Gateway basic symbols and Artifacts are not available in Gantt Charts. Finally, it should be noted that Pools, Lanes, Groups and Text Annotations can be easily and graphically inserted in the Gantt Charts without abrupting the integrity of their representations.

5. In accordance with (Awad, 2013), the one-to-one correspondence of Petri nets symbols with the respective ones of BPMN, classic flowcharts and Gantt charts urges the combination of the Petri Nets basic symbols presented in Table 4. Similarly to Gantt Charts, the step from the project scheduling to business process modeling demands modifications and for the previous reasons a lot of modifications have been applied to Flow Objects. Anyway, Petri Nets are proven to be very adaptive to Gateway conditions where smart combinations of Places and Transitions imitate the vast majority of BPMN Gateway symbols without important modifications. Note that the demand for concatenations of Places and Transitions creates the need for inserting virtual Places (dashed circles) in the Petri Net basic element symbols of the proposed simplified business educational equivalence table so that the validation of the Petri nets can be made by a Petri net simulator.

6. Again, similarly to Gantt Charts, descriptive modifications have been made to Connecting Objects while Pools, Lanes, Groups and Text Annotations are graphically inserted in the Petri Nets without disrupting their character.

The study of Table 5 and the previous observations show that a need for an initial modification of the existing documentation in the enterprise should be made so that the elements involved in the existing business process model diagrams are of the Table 5 regardless of the applied business process model (e.g., if an enterprise's subdepartment uses Classic Flowcharts and there are a lot of Decision symbols in its diagrams, here, each Decision symbol should first modified in compliance with the Conversion Cases 11 to 15). Afterwards, the one-to-one correspondence of Table 5 allows the conversion from one business process model to another. Therefore, in the following Section, a real case scenario of conversion from BPMN without modifications to all business process models of this paper is analytically presented. 
Table 5. The proposed simplified business educational equivalence table

\begin{tabular}{|c|c|c|c|c|c|c|}
\hline $\begin{array}{l}\text { BPMN } \\
\text { Diagram } \\
\text { Category of } \\
\text { Elements }\end{array}$ & $\begin{array}{c}\text { BPMN } \\
\text { Diagram Basic } \\
\text { Element Name }\end{array}$ & $\begin{array}{l}\text { BPMN Diagram Basic } \\
\text { Element Symbol }\end{array}$ & $\begin{array}{c}\text { Classic Flowchart Basic } \\
\text { Element Symbol }\end{array}$ & $\begin{array}{l}\text { Gantt Charts Basic } \\
\text { Element Symbol }\end{array}$ & $\begin{array}{l}\text { Petri Nets Basic Element } \\
\text { Symbol (Awad, 2013) }\end{array}$ & $\begin{array}{l}\text { Con- } \\
\text { version } \\
\text { Case ID }\end{array}$ \\
\hline & $\begin{array}{l}\text { Event } \\
\text { (Start) }\end{array}$ & & & & & 1 \\
\hline & $\begin{array}{c}\text { Event } \\
\text { (Intermediate) }\end{array}$ & & & & & 2 \\
\hline & $\begin{array}{l}\text { Event } \\
\text { (End) }\end{array}$ & & & & & 3 \\
\hline & $\begin{array}{l}\text { Event } \\
\text { (Message } \\
\text { Trigger) }\end{array}$ & & & & & 4 \\
\hline & $\begin{array}{l}\text { Event } \\
\text { (Timer } \\
\text { Trigger) }\end{array}$ & & & & & 5 \\
\hline $\begin{array}{l}\text { Flow } \\
\text { Objects }\end{array}$ & $\begin{array}{l}\text { Event } \\
\text { (Business } \\
\text { Rule) }\end{array}$ & & & B & & 6 \\
\hline & $\begin{array}{c}\text { Activity } \\
\text { (Generic Use) }\end{array}$ & $\begin{array}{l}\text { Activity start date/time, } \\
\text { Activity duration and } \\
\text { Activity end date/time } \\
\text { inside the associated } \\
\text { Activity }\end{array}$ & $\begin{array}{l}\text { Process start date/time, } \\
\text { Process duration and Pro- } \\
\text { cess end date/time inside } \\
\text { the associated Process }\end{array}$ & & & 7 \\
\hline & $\begin{array}{l}\text { Activity } \\
\text { (for Input/ } \\
\text { Output) }\end{array}$ & $\begin{array}{l}\text { Activity start date/time, } \\
\text { Activity duration and } \\
\text { Activity end date/time } \\
\text { inside the associated } \\
\text { Activity }\end{array}$ & $\begin{array}{l}\text { Process start date/time, } \\
\text { Process duration and Pro- } \\
\text { cess end date/time inside } \\
\text { the associated Input/Output } \\
\text { Process }\end{array}$ & $\mathrm{I} / \mathrm{O}$ & $\mathrm{O}$ & 8 \\
\hline & $\begin{array}{l}\text { Message } \\
\text { Event } \\
\text { (Send } \\
\text { Message) }\end{array}$ & & SM & SM & & 9 \\
\hline & $\begin{array}{l}\text { Message } \\
\text { Event } \\
\text { (Receive } \\
\text { Message) }\end{array}$ & & $\mathrm{RM}$ & RM & SM & 10 \\
\hline
\end{tabular}


Gateway

(Parallel Fork)

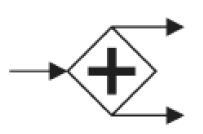

Gateway

(Parallel Join)
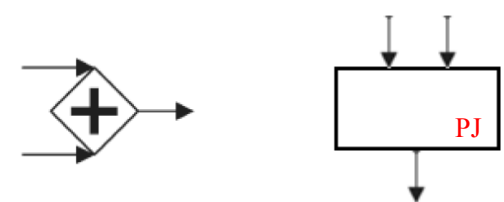

Description inside the associated Task

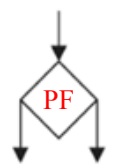

Description inside the associated Task
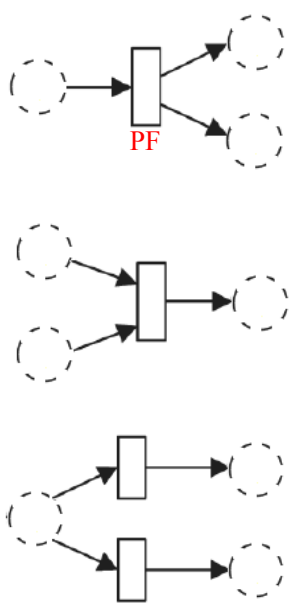

Description inside

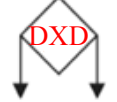

the associated Task

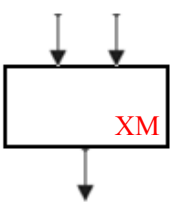

Description inside the associated Task

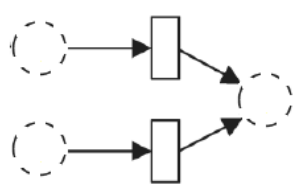
XOR Merge
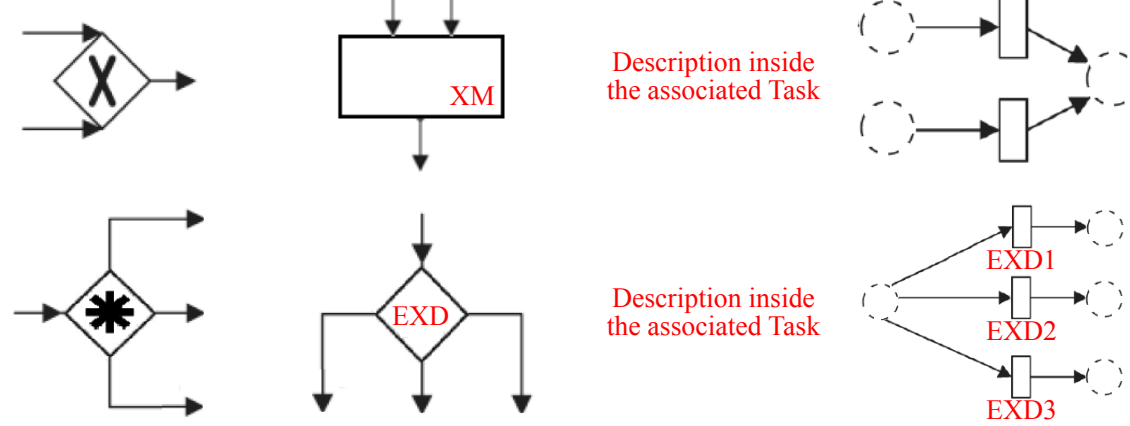

15

(Event-based

XOR

Decision)

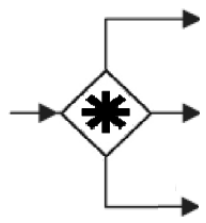

Description inside the associated Task

$\nabla$

$\nabla$

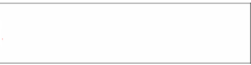

16

Swimlanes

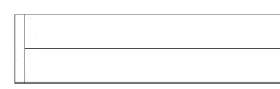

$\nabla$

Data Object

Database

Artifacts

Group $\square$

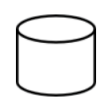

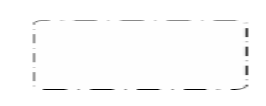

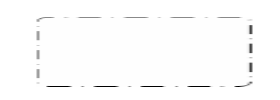

Description inside the associated Task

$\stackrel{A}{\rightarrow} \stackrel{A}{\rightarrow} \square$

Description inside the associated Task
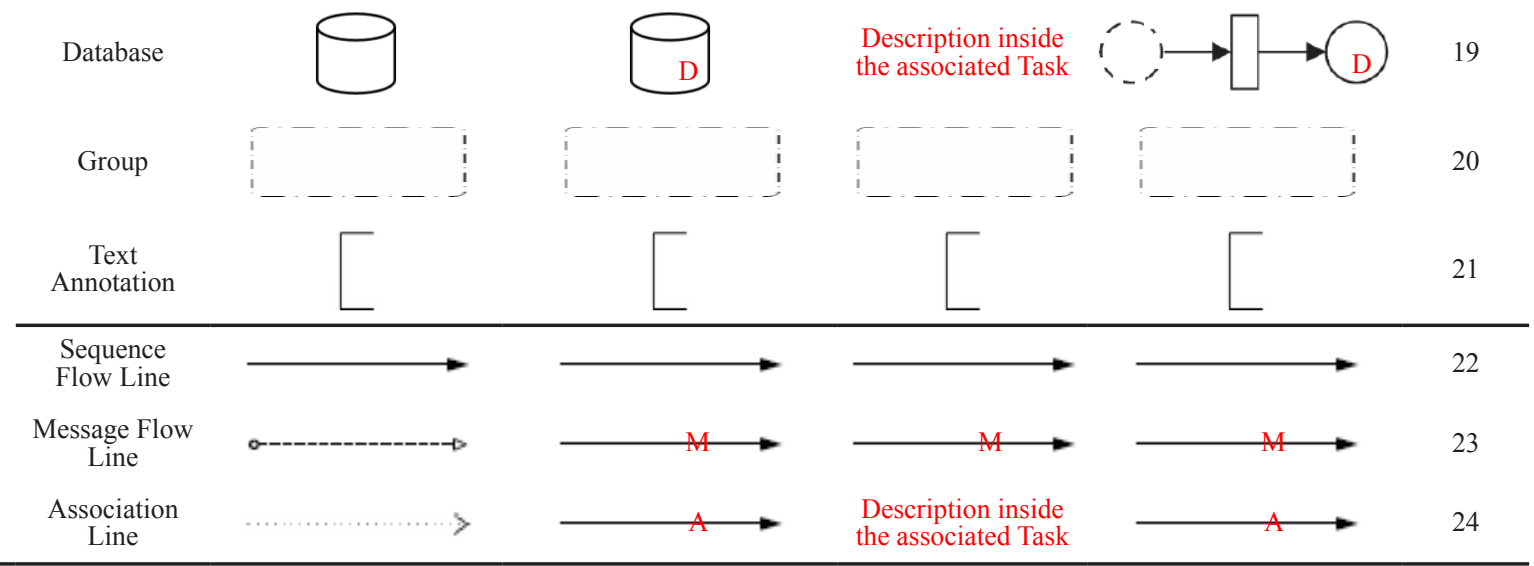

Connecting Message Flow Objects

Association the associated Task

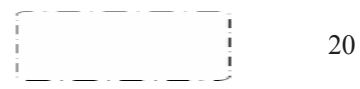




\section{The notation alignment and the equivalence rules among enterprise's business process models-case study and discussion}

In this paper, a bridging approach to make the four business process models equivalent or easily complementary is here proposed in terms of process modeling and it is implied that there is already available an initial diagram in the enterprise's subdepartment that needs to be converted into the other three remaining business process models. Hence, as the basic elements of the initial diagram are identified, the other three remaining business process diagrams are identified through the proposed business education equivalence table of Table 5 and its one-to-one correspondence among the basic elements of the four business process models. In this Section, a case study concerning the conversions among the four process modeling standards of interest, say, BPMN diagram, classic flowchart, Gantt chart and Petri net, is presented by following the guidelines of Section 2 and Table 5.

\subsection{Unmodified BPMN diagram and modified BPMN diagram in accordance with the simplified business educational equivalence table}

In Figure 1(a), one real unmodified BPMN diagram of an enterprise's process is shown. In order to proceed towards the notation alignment and the equivalence rules among the four process modeling standards of interest, certain initial modifications that are complied with Table 5 are made and the modified BPMN diagram is given in Figure 1(b) as well as the necessary modifications in red color.

By comparing Figures 1(a) and 1(b), interesting remarks can be pointed out concerning the applied modifications in BPMN diagrams, namely:

1. Both BPMN diagrams are validated in Microsoft Visio 2016. The applied BPMN diagram validation rules of Microsoft Visio check the visual correctness of the unmodified and modified BPMN diagrams against logical rules specified in the BPMN standard. The validation of the BPMN diagrams imply that the unmodified and modified BPMN diagram logically and well describe the examined business process while the applied modifications do not affect this validity.

2. In accordance with the conversion case 7 of Table 5, time requirements are added in the Activities of the modified BPMN diagram so that the respective Gantt chart can be designed afterwards. Note that the Message Events involving send and receive messages do not demand the insertion of temporal constraints but are properly defined to allow the one-to-one correspondence with the following process model diagrams.

3. In accordance with the conversion cases 5 and 3 of Table 5, the events of Time Trigger and End have been reported in the modified BPMN diagram, respectively.

4. The main difficulty concerning the conversion from the unmodified BPMN diagram to the modified one is the characterization of the used Gateways that may require an interview of the involved personnel. In the business process of interest, Gateways 01 and 02 are a parallel join gateway and an event-based XOR decision gateway, respectively. On the basis of the previous finding and in accordance with the conversion cases 12 and 15 of Table 5, Gateways 01 and 02 are analytically represented in the modified BPMN diagram of Figure 1(b).

Since the modified BPMN diagram is now complied with the requirements of the simplified business educational equivalence table, which is given in Table 5, the goal of the following subsections is to underline the one-to-one correspondence of basic elements in the remaining three process modeling standards of interest, say, classic flowchart, Gantt chart and Petri net.

\subsection{Classic flowchart in accordance with the simplified business educational equivalence table}

In Figure 2, the classic flowchart of the enterprise's process of Figure 1(b) is demonstrated in accordance with the simplified business educational equivalence table given in Table 5. Note that the modified BPMN diagram of Figure 1(b) is used instead of the unmodified BPMN diagram of Figure 1(a) since the conversion procedure is a straightforward conversion process in this case. 

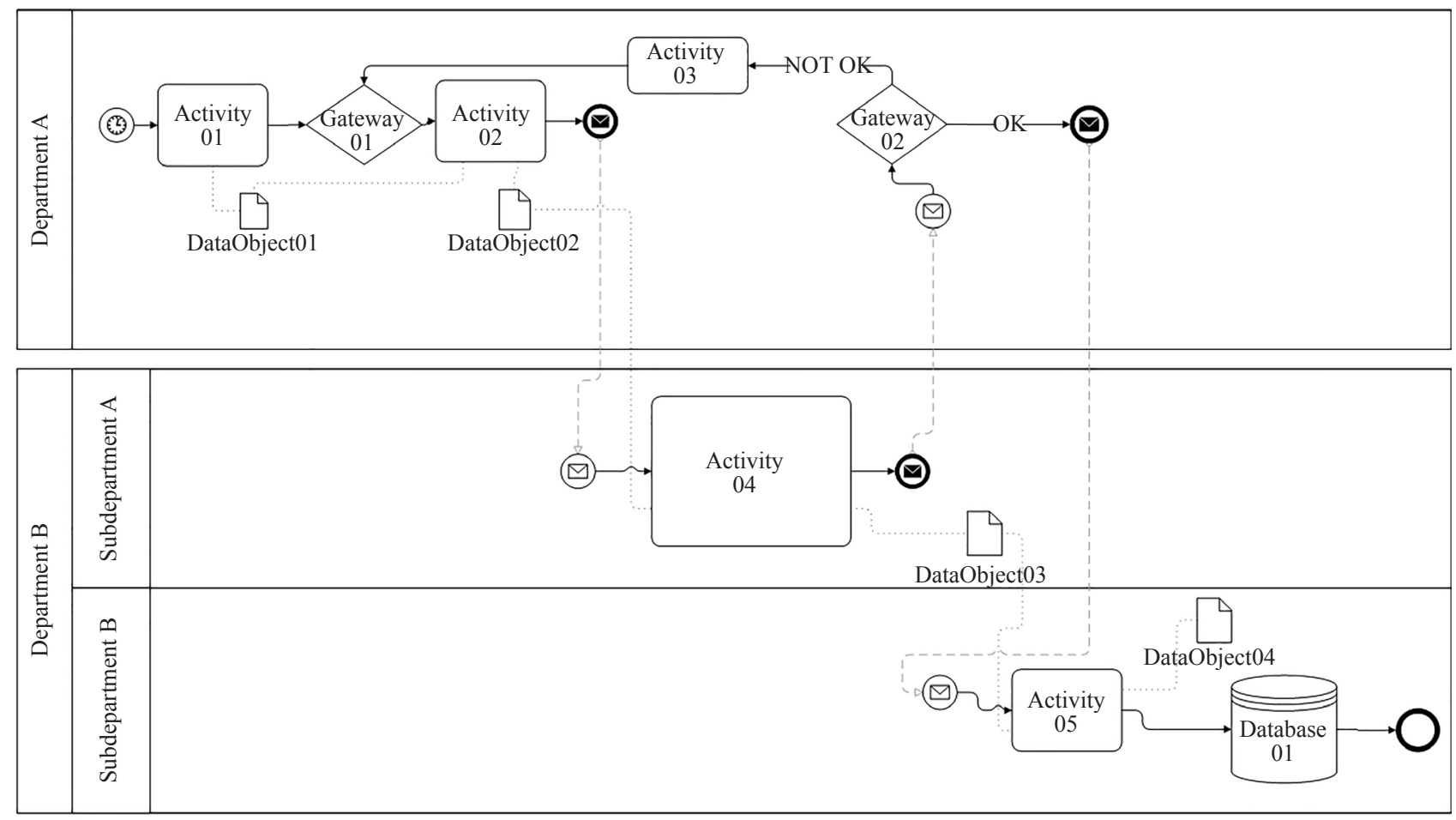

(a)
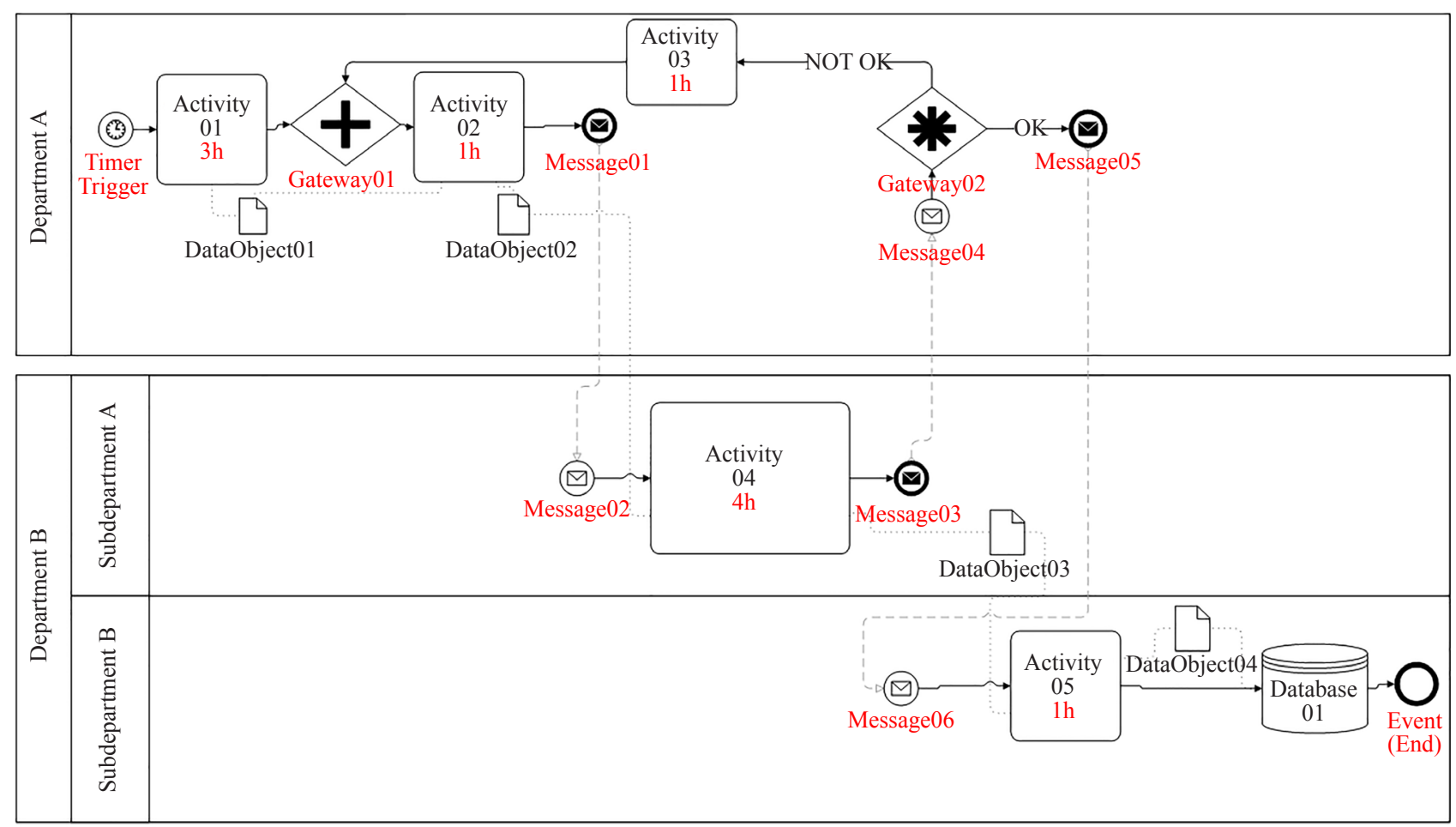

(b)

Figure 1. BPMN diagrams of a real enterprise's process: (a) The unmodified diagram; (b) The modified diagram 


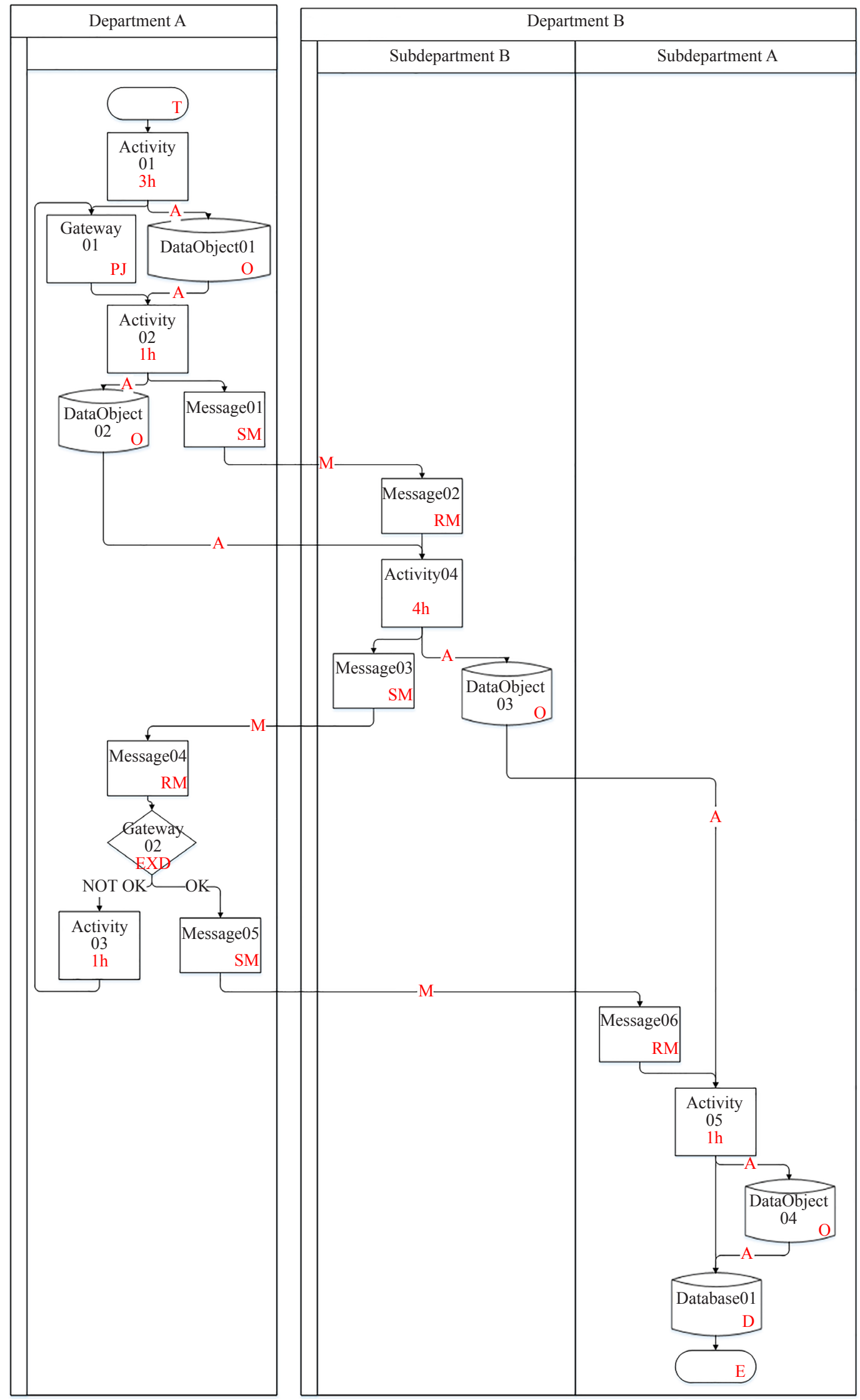

Figure 2. Classic flowchart of the real enterprise's process 
By comparing Figures 2 and 1(b), classic flowcharts and BPMN diagrams present significant similarities since a heredity between these two types of business process diagrams has already been identified in Section 2.2 but a number of differences can also be observed due to the different degrees of richness of the basic symbol portfolios of classic flowcharts and BPMN diagrams. The following observations are mentioned:

1. Similarly to BPMN diagrams, the classic flowchart of Figure 2 is validated by Microsoft Visio 2016. As already been mentioned, the popular vertical orientation of classic flowcharts is here adopted.

2. Similarly to BPMN diagrams, the time requirements of each Process are added across the classic flowchart. The only Processes that do not include the temporal constraints are the Processes that involve sending or receiving messages.

3. As the Gateways are regarded, their accurate characterization in Figure 1(b) and the simplified business educational equivalence table of Table 5 significantly help towards their representation in Figure 2. More analytically, Gateways 01 and 02 are a parallel join gateway and an event-based XOR decision gateway, respectively, and the respective basic symbols are shown in Figure 2 as mandated by the conversion cases 12 and 15 of Table 5, respectively.

4. Conversely to the modified BPMN diagram of Figure 1(b), the big issue is that the classic flowcharts have a small variety in connecting objects. According to the conversion cases 22, 23 and 24, message flow lines and association lines that are adopted in Figure 2 exploit the same arrow with the sequence flow lines but message flow lines and association lines are differentiated by the insertion of the corresponding red initial letters. This modification allows the one-to-correspondence among the diagrams of the process modeling standards of interest.

The one-to-one correspondence of basic elements that is offered by the simplified business educational equivalence table has allowed the straightforward conversion of the BPMN diagram of Figure 1(b) to the classic flowchart of Figure 2. In the following subsection, Gantt chart is going to be developed as a business process model rather than a time and resource management representation method.

\subsection{Gantt charts in accordance with the simplified business educational equivalence table}

In Table 6, the Gantt chart of the enterprise's process of Figures 1(b) and 2 is demonstrated in accordance with the simplified business educational equivalence table given in Table 5. Note that Table 6 focuses on the business process modeling rather on the time management and for that reason the time allocation axis, the durations of the Tasks and the predecessor Tasks are used so that Microsoft Visio can create the unmodified Gantt chart that is further processed and here presented in Table 6 .

By comparing Table 6 with Figures 2 and 1(b), it is obvious that Gantt charts require a lot of additional requirements, which are unnecessary for the other three process modeling standards of interest, that are suitable for the time management rather than the business process modeling. Anyway, Gantt charts can contribute to the spatiotemporal representation of the business processes and subprocesses. During the conversion of BPMN diagram of Figure 1(b) to the Gantt Chart of Table 6, the following details are reported, namely:

1. Although all the time requirements of Tasks 3, 4, 8, 12 and 16 are in agreement with the time requirements of the respective Activities 01, 02, 03, 04 and 05, the time duration of tasks that involve sending and receiving messages has been assumed to be equal to $1 \mathrm{~min}$ (or $0.02 \mathrm{~h}$ by Microsoft Visio). This has been done in order to prevent the automatic conversion of Message Tasks to milestones by Microsoft Visio. Also, each Message Task has been differentiated with the corresponding red annotation (say, SM or RM) in compliance with the conversion cases 9 and 10. Note that the time required for the preparation, sending and/or receiving of the messages can be calculated and taken into account during the preparation of business process model diagrams as in the case of other Tasks.

2. The Gantt chart of Table 6 has been redesigned in Microsoft Project 2016 and there validated. In fact, the validation of the Gantt chart is achieved without the red link line of Table 6 and this is due to the fact that Tasks 4 and 8 are already linked through another task chain. Anyway, since the business process representation is the main interest of this paper, the red link line between the Tasks 4 and 8 has been manually designed in the Gantt chart of Table 6 .

3. The main disadvantage of the Gantt chart of Table 6 is the lack of corresponding basic symbols to the gateway basic symbols of the BPMN diagrams as well as the produced task chains. Already been identified in the simplified business educational equivalence table of Table 5, Gateways 01 and 02 of the BPMN diagram of Figure 1(b) are described inside the associated Tasks 4 and Tasks 7, 8 as mandated by the conversion cases 12 and 15 of Table 5, respectively. In addition, the input Tasks and output Tasks of Gateways 01 and 02 are also reported in Table 6.

4. Similarly to the gateway disadvantage, artifacts of the BPMN diagram of Figure 1(b), such as DataObject01, 
DataObject02, DataObject03, DataObject04 and Database01, cannot be explicitly represented in the Gantt charts and for that reason all the aforementioned artifacts have been described inside the associated Tasks.

5. Similarly to the classic flowcharts, Gantt charts suffer from a small variety of link lines. According to the conversion case 23 , link lines concerning message flow lines are differentiated by the insertion of the corresponding red letter M. Conversely to classic flowcharts, associations are implied and described inside the Tasks involving artifacts.

Table 6. Gantt chart of the real enterprise's process

\begin{tabular}{|c|c|c|c|c|c|c|c|c|c|c|c|c|c|c|c|c|c|c|c|}
\hline \multirow[t]{2}{*}{ ID } & \multirow[t]{2}{*}{ Task Name } & \multirow[t]{2}{*}{ Duration } & \multirow[t]{2}{*}{ Predecessors } & & & & & & & & & & & & & & & & \\
\hline & & & & 12 & 1 & 2 & 3 & 4 & 5 & 6 & 7 & 8 & 9 & 10 & 11 & 12 & 1 & 2 & 3 \\
\hline 1 & Department A & $9.06 \mathrm{~h}$ & & & $\bar{E}$ & & & & & & $=$ & -7 & & & & & & & \\
\hline 2 & Start & $0 \mathrm{~h}$ & & & & & & & & & & & & & & & & & \\
\hline 3 & $\begin{array}{l}\text { Activity01 [Gateway01 (Parallel } \\
\text { Join) Input] + DataObject01 }\end{array}$ & $3 \mathrm{~h}$ & 2 & & & & & & & & & & & & & & & & \\
\hline 4 & $\begin{array}{l}\text { Activity02 [Gateway01 (Parallel } \\
\text { Join) Output] + DataObject02 } \\
\text { (Manual Predecessor: Activity03) }\end{array}$ & $1 \mathrm{~h}$ & $3 ;(8)$ & & & & & & & & & & & & & & & & \\
\hline 5 & Message 01 & $0.02 \mathrm{~h}$ & 4 & & & & & & & & & & & & & & & & \\
\hline 6 & $\begin{array}{l}\text { Message04 [Gateway02 (Event- } \\
\text { based XOR Decision) Input] }\end{array}$ & $0.02 \mathrm{~h}$ & 13 & & & & $\mathrm{M}$ & & & & & & & & & & & & \\
\hline 7 & $\begin{array}{l}\text { Message05 [Gateway02 (Event- } \\
\text { based XOR Decision) Output: OK] }\end{array}$ & $0.02 \mathrm{~h}$ & 6 & & & & & & & & & M & & & & & & & \\
\hline 8 & $\begin{array}{c}\text { Activity03 [Gateway01 (Parallel } \\
\text { Join) Input] [Gateway02 (Event- } \\
\text { based XOR Decision) Output: } \\
\text { NOT OK] }\end{array}$ & $1 \mathrm{~h}$ & 6 & & & & & & & & & & & & & & & & \\
\hline 9 & Department B & $5.1 \mathrm{~h}$ & & & & & & & & & & & & & & & & & \\
\hline 10 & Subdepartment A & $4.02 \mathrm{~h}$ & & & & & & & & & & & & & & & & & \\
\hline 11 & Message 02 & $0.02 \mathrm{~h}$ & 5 & & & & & & & & & & & & & & & & \\
\hline 12 & Activity04 + DataObject03 & $4 \mathrm{~h}$ & 11 & & & & & & & & & & & & & & & & \\
\hline 13 & Message 03 & $0.02 \mathrm{~h}$ & 12 & & & & & & & & Mt & & & & & & & & \\
\hline 14 & Subdepartment B & $1.01 \mathrm{~h}$ & & & & & & & & & & $\mathrm{M}$ & & & & & & & \\
\hline 15 & Message 06 & $0.02 \mathrm{~h}$ & 7 & & & & & & & & & & & & & & & & \\
\hline 16 & $\begin{array}{c}\text { Activity05 + DataObject04 + } \\
\text { Database } 01\end{array}$ & $1 \mathrm{~h}$ & 15 & & & & & & & & & & & & & & & & \\
\hline 17 & End & $0 \mathrm{~h}$ & 16 & & & & & & & & & & $\mathrm{E}$ & & & & & & \\
\hline
\end{tabular}

It is obvious that the one-to-one correspondence of basic elements, which is delivered by the simplified business educational equivalence table, requires hard description work in the involved Tasks of the equivalent Gantt Chart. Even if the Gateways are well defined by the description of Tasks, the Gantt chart loses the required intuitiveness of the process model diagrams. Synoptically, Gantt charts can decently model business processes by exploiting the simplified business educational equivalence table but Gantt charts cannot be the first choice among the process modeling standards of this paper when decisions need to occur. In the following subsection, Petri nets are going to be developed and assessed as a business process model rather than a network simulator.

\subsection{Petri nets in accordance with the simplified business educational equivalence table}

In Figure 3, the Petri net of the enterprise's process of Figures 1(b), 2 and Table 6 is demonstrated in accordance with the simplified business educational equivalence table given in Table 5. Note that Figure 3 focuses on the business 
process modeling rather on the network simulation and for that reason tokens are not considered during the Petri net design. Microsoft Visio 2016 is used for the Petri net design of Figure 3.

By comparing Figure 3 with Figures 1(b), 2 and Table 6, Petri nets can reliably represent business processes in diagrams if the simplified business educational equivalence table is adopted. Indeed, Petri net of Figure 3 after the modifications of Table 5 gives an image similar to the BPMN diagram of Figure 1(b) and the classic flowchart of Figure 2. As the implementation of the Petri net is concerned, the following remarks are given, namely:

1. As already been mentioned, Figure 3 has been designed in Microsoft Visio 2016 but there is not a preinstalled validation process in Microsoft Visio as in the cases of the BPMN diagrams and the classic flowcharts. To validate the demonstrated Petri net, HPetriSim has been used. On the basis of the design requirements of HPetriSim and the Table 5, virtual Places, which are designed as dashed circles in Figure 3, have been inserted to the Petri net so that the validation is feasible in HPetriSim. Apart from the one-to-one correspondence that is anyway easily available from Table 5, the insertion of virtual Places remains the most difficult step towards the preparation of the Petri net diagram since a sequence of Places and Transition is required anywhere in the Petri nets.

2. As the Swimlanes are regarded (i.e, Pools and Lanes of the respective conversion cases 16 and 17), BPMN diagrams and Petri nets maintain both the same organizational order and the same flow orientation.

3. Conversely to Gantt charts, Petri nets maintain the visual understandability and intuitiveness of the BPMN diagrams and the classic flowcharts. Similarly to the BPMN diagrams and the classic flowcharts, the descriptions that are required to fully describe the one-to-one correspondence of the involved basic elements are the absolutely necessary ones.

4. Although this paper focuses on the graphical representation of the business processes, the implementation of Figure 3 combined with the insertion of Tokens may allow the simulation of the business process operation. The aforementioned simulation may allow the business process reengineering as well as the easier digital transformation of the subdepartments, departments and the entire enterprise by optimizing the required objectives in each examined scenario.

Petri nets may become a valuable accompanying tool to the BPMN diagrams during the digital transformation of enterprises, since Petri nets can offer both graphical representation possibilities and dynamic simulation capabilities of the examined business processes. Anyway, Petri nets cannot surpass the intuitiveness of BPMN diagrams and of classic flowcharts since Petri nets demand the insertion of virtual Places for their validation and simulation.

\subsection{Discussion of the results}

The proposed simplified business educational equivalence table, which is shown in Table 5, offers the one-to-one correspondence, the notation alignment and the equivalence rules of the four process modeling standards of interest, say, BPMN diagram, classic flowchart, Gantt chart and Petri net. As the objective of this paper is to offer an easy method for the non-specialized personnel to convert business process diagrams among the aforementioned four process modeling standards, the intuitiveness of the graphical representations remains the main goal. Hence, through the prism of the intuitiveness of the graphical representations, BPMN diagrams remain the most convenient way to describe business processes. Due to their rich portfolio of basic symbols, BPMN diagrams are not considered by chance the state-of-art business process model. Classic flowcharts and Petri nets can also decently act as business process models of the graphical representations of the business processes while Gantt charts need to be exhaustively descriptive in order to allow the one-to-one correspondence with the other three process modeling standards of this paper. Here, it should be noted that Petri nets can also act as an accompanying tool to the BPMN diagrams since Petri nets offer the simulation option that may allow the optimization of the business processes towards the enterprise's digital transformation.

The scope of the proposed simplified business educational equivalence table is to be used by the enterprise's nonspecialized personnel so that a degree of the notation alignment and the equivalence rules among the four process modeling standards can be achieved. To accomplish the goal of the notation alignment and the equivalence rules of the four process modeling standards of interest, enterprises should invest in: (i) Digital and IT Technology Infrastructure: all the specialized and non-specialized personnel that is involved in the notation alignment project should keep all the necessary software licenses (e.g, Microsoft Visio and Project licenses). In addition, to further accelerate the business process integration and collaboration, cloud-based solutions (e.g., Microsoft OneDrive and SharePoint) may allow the instant file access/sharing and the co-authoring. Anyway, open source software solutions can be promoted in smaller 


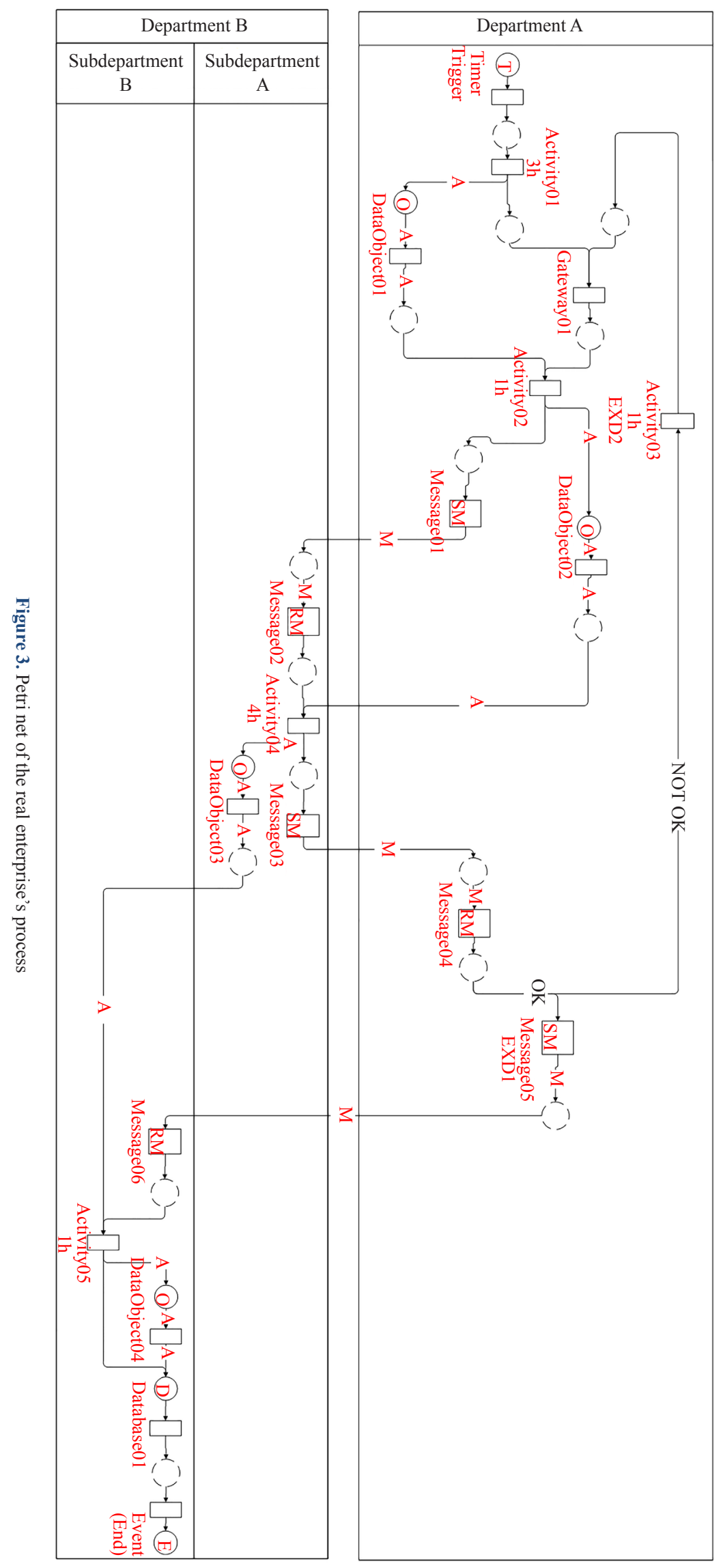


enterprises in order to reduce their costs; and (ii) Business Education and Training: It is obvious that the involved personnel should be educated and trained in the fields of business process modeling standards, in the simplified business educational equivalence table of this paper and in the required digital and IT technology infrastructure, which has been aforementioned. Anyway, under the background of the digital transformation of enterprises, enterprises' training programs should be focused on the challenges of business process modeling and digital/IT technology integration.

Nonetheless, the goal of the enterprise's digital transformation requires a more organized approach such as a creation of a specialized and responsible directoriate and/or department and/or subdepartment in the enterprise. For example, in a power utility enterprise, IT department, either as a whole department or as its subdepartments, can be responsible for the supervision and the coordination of the business process modeling efforts and results across the entire enterprise's environment. Therefore, apart from the other IT responsibilities, such as the smart grid operation, the energy theft detection, microgrids, power trading, fault localization, electric vehicles, etc (Lazaropoulos, 2019; Lazaropoulos \& Lazaropoulos, 2015; Lazaropoulos, 2017; Lazaropoulos, 2020), IT department of a power utility may significantly contribute towards the digital transformation by supporting the business process modeling across the enterprise. Here, it should be reminded that the continuous optimization of the business process modeling remains a systematic strategic enterprise's decision towards the digital transformation that presupposes managerial implications and practical insights of other applications. However, great benefits, such as fully dynamic-live enterprise's repository for strategic decisions, reduced process costs, increased process quality, increased forecast accuracy, etc, are expected after the integration of the business process modeling (Lampathaki et al., 2013; Hoggett \& Shah, 2013).

Finally, new future research steps can be pursued on the basis of the notation alignment and equivalence rules among the four process modeling standards. First, the study of other well-known business process models, such as the Integration Definition (IDEF) modeling languages and Unified Modeling Language (UML), and their further integration with the proposed simplified business educational equivalence table of this paper, can become a short-term research goal. Second, the proposal of an integrated or universal business process model that can exploit the strong points of all the aforementioned integrated business process models may be a long-term research pious desire.

\section{Conclusions}

In this paper the simplified business educational equivalence table has been proposed so that four process modeling standards, say, BPMN diagram, classic flowchart, Gantt chart and Petri net, which are extensively used for business process modeling in the enterprises, can be notationally aligned among them. The basic advantages of the proposed simplified business educational equivalence table are: (i) the one-to-one correspondence among the aforementioned four process modeling standards; and (ii) the easiness of the conversions and the required modifications by non-specialized personnel. Also, the coexistence of the aforementioned four process modeling standards has been assessed by adopting the suggested modifications of the simplified business educational equivalence table. It has been shown that BPMN standard may act as the process modeling standard basis due to its rich portfolio of basic symbols, its high intuitiveness of its diagrams and the low number of the required modifications for the notation alignment and the equivalence rules. Classic flowcharts remain the first alternative for the business process modeling after the BPMN diagrams; the basic symbols of the classic flowcharts are well known, the intuitiveness of classic flowcharts remains strong and the required verbal description for the conversion issues of the simplified business educational equivalence table is relatively low. In contrast, Gantt Charts cannot be considered as the process modeling standard basis since they are more suitable for the time and resource management rather than the business process modeling; poor portfolio of basic symbols, great number of required modifications for the notation alignment and the equivalence rules and great need for verbal descriptions are the main disadvantages of applying Gantt Charts for business process modeling. As the Petri nets are concerned, by applying the required modifications dictated by the simplified business educational equivalence table, Petri nets can be considered as a decent model for the description of business processes. The main advantage of Petri nets is their simulation capabilities that can offer a dynamic image of the business processes. Petri nets are a valuable help towards the business process reengineering and the digital transformation, whereas their main disadvantage is the careful insertion of basic elements so that valid Petri nets can be defined. Anyway, the one-to-one correspondence is secured in all the cases examined thanks to the proposed simplified business educational equivalence table and all the conversions remain a relatively easy task in all the cases for the non-specialized personnel of an enterprise. Finally, it has been 
recognized that an enterprise's digital transformation requires intensive work during the business process modeling and for that reason either IT department or its subdepartments may focus on the business process modeling standards and their notation alignment.

\section{References}

Aldin, L., \& Cesare, S. (2011). A literature review on business process modelling: New frontiers of reusability. Enterprise Information Systems, 5(3), 359-383.

Allweyer, T. (2016). BPMN 2.0: Introduction to the standard for business process modeling. BoD-Books on Demand.

Anschuetz, H. (2018, November). HPetriSim 0.9 beta. https://github.com/Uzuul23/HPetriSim/releases/tag/0.9

Awad, A. (2013). BPMN to petri nets mapping (introduction). Educational Notes IS333-Management Information System, Cairo University. https://scholar.cu.edu.eg/?q=imanhelal/files/is333_mis_lab8_2013.pdf

Bauskar, E. B., \& Mikolajczak, B. (2006). Abstract node method for integration of object oriented design with colored petri nets. Third International Conference on Information Technology: New Generations (ITNG'06) (pp. 680-687).

Ben-Daya, M., Duffuaa, S. O., Raouf, A., Knezevic, J., \& Ait-Kadi, D. (2009). Handbook of maintenance management and engineering. Springer.

Burkhard, R. A., Michael, M., Rodgers, P., Smis, MTJ., \& Stott, J. (2005). Knowledge visualization: A comparative study between project tube maps and Gantt charts. In 5th International Conference on Knowledge Management (pp. 388-395). Springer.

Cahyani, R. D., Heroza, R. I., Indah, D. R., Septiani, A., \& Bernova, N. M. (2020). Organizational knowledge representation using flowcharts with POS tagger techniques for Bahasa. In Sriwijaya International Conference on Information Technology and Its Applications (SICONIAN 2019) (pp. 566-571). Atlantis Press.

Chinosi, M., \& Trombetta, A. (2012). BPMN: An introduction to the standard. Computer Standards \& Interfaces, 34(1), 124-134.

Dijkman, R. M., Dumas, M., \& Ouyang, C. (2008). Semantics and analysis of business process models in BPMN. Information and Software Technology, 50(12), 1281-1294.

Draheim, D. (2010). Business process technology: A unified view on business processes, workflows and enterprise applications. Springer Science \& Business Media.

El Hichami, O., Al Achhab, M., Berrada, I., \& El Mohajir, B. E. (2014). Visual specification language and automatic checking of business process. In VECoS (pp. 93-101).

Flores, C., \& Sepúlveda, M. (2010). Temporal specification of business processes through project planning tools. In International Conference on Business Process Management (pp. 85-96). Springer.

Geraldi, J., \& Lechter, T. (2012). Gantt charts revisited: A critical analysis of its roots and implications to the management of projects today. International Journal of Managing Projects in Business, 5(4), 578-594.

Gilbreth, F. B., \& Gilbreth, L. M. (1921). Process charts. American Society of Mechanical Engineers.

Grigorova, K., \& Mironov, K. (2014). Comparison of business process mmodeling standards. International Journal of Engineering Sciences \& Management Research, 1(3), 1-8.

Hoggett, C., \& Shah, P. (2013). Maximizing the value of enterprise process modeling: Process governance in large scale transformation programs. BPTrends. http://www.bptrends.com/publicationfiles/03-05-2013-ART-MaximizingValueProcessModeling-Purav\%20Shah.pdf

IBM. (1969). Flowcharting Techniques Technical Report GC20-8152-1 edition.

International Organization for Standardization (ISO). (1985). ISO 5807:1985 Technical Standard Report.

Kelemen, Z. D., Kusters, R., Trienekens, J., \& Balla, K. (2013). Selecting a process modeling language for process based unification of multiple standards and models. Budapest, Technical Report TR201304.

Kumar, P. P. (2005). Effective use of Gantt chart for managing large scale projects. Cost engineering, 47(7), $13-21$.

Lampathaki, F., Koussouris, S., \& Psarras, J. (2013). Business process modelling, business process reengineering technical report 2013 of decision support systems laboratory NTUA. http://academics.epu.ntua.gr/LinkClick.aspx?fileticket $=$ nNPcBN7bjX0\%3D\&tabid=930\&mid $=2218$

Lazaropoulos, A. G., \& Lazaropoulos, P. (2015). Financially stimulating local economies by exploiting communities’ microgrids: Power trading and hybrid techno-economic (HTE) model. Trends in Renewable Energy, 1(3), $131-184$. http://futureenergysp.com/index.php/tre/article/view/14

Lazaropoulos, A. G. (2017). Main line fault localization methodology in smart grid-Part 3: Main line fault localization methodology (MLFLM). Trends in Renewable Energy, 3(3), 62-81. http://futureenergysp.com/index.php/tre/article/ 
view/38

Lazaropoulos, A. G. (2019). The role of information technology department against the hook style energy theft in smart cities-ad-hoc overhead low-voltage broadband over power lines (OV LV BPL) networks. Trends in Renewable Energy, 5(2), 117-150. http://futureenergysp.com/index.php/tre/article/download/93/pdf

Lazaropoulos, A. G. (2020). Business analytics and IT in smart grid-part 3: New application aspect and the quantitative mitigation analysis of piecewise monotonic data approximations on the iSHM class map footprints of overhead low-voltage broadband over power lines topologies contaminated by measurement differences. Trends in Renewable Energy, 6(2), 214-233. http://futureenergysp.com/index.php/tre/article/view/119/pdf

Lee, S., \& Shvetsova, O. A. (2019). Optimization of the technology transfer process using gantt charts and critical path analysis flow diagrams: Case study of the korean automobile industry. Processes, 7(12), 1-27.

Maung, Y. W. M., \& Hein, A. A. (2014). Colored petri-nets (cpn) based model for web services composition. IJCCER, 2(5), 169-172.

Microsoft. (2012, November 19). Introducing BPMN 2.0 in Visio. https://www.microsoft.com/en-us/microsoft-365/ blog/2012/11/19/introducing-bpmn-2-0-in-visio/

Microsoft. (n.d.). Create a cross-functional flowchart in Visio for the web. https://support.microsoft.com/en-us/office/ create-a-cross-functional-flowchart-in-visio-for-the-web-3546da67-a092-431a-b47a-bbb808edf581

Murata, T. (1989). Petri nets: Properties, analysis and applications. Proceedings of the IEEE, 77(4), 541-580.

Mutarraf, U., Barkaoui, K., Li, Z., Wu, N., \& Qu, T. (2018). Transformation of business process model and notation models onto petri nets and their analysis. Advances in Mechanical Engineering, 10(12), 1-21.

Myler, H. R. (1998). Fundamentals of engineering programming with C and Fortran. Cambridge University Press.

Object Management Group (OMG). (2011, January 3). Business process model and notation (BPMN)-version 2.0 technical report. https://www.omg.org/spec/BPMN/2.0/PDF

Pathak, K. S. (2015). The advantages of using project management tools in industries. International Journal of Scientific Research in Science, Engineering and Technology, 1(1), 228-236.

Pucher, M. J. (2012, June 7). When to use a flow-diagram for process and when not. https://isismjpucher.wordpress. com/2012/06/07/when-to-use-a-flow-diagram-for-process-and-when-not/

Rajabi, B. A., \& Lee, S. P. (2009). Change management in business process modeling survey. In Proc. IEEE 2009 International Conference on Information Management and Engineering (pp. 37-41).

Sarab, M. M., Shahrokhi, M., \& Tabatabaei, O. (2020). A structured approach for display of the most practical theories in ELT. Journal of Critical Studies in Language and Literature, 1(3), 36-55.

Shelly, G. B., \& Vermaat, M. E. (2013). Bundle: Enhanced discovering computers, complete your interactive guide to the digital world. Computer Concepts CourseMate with eBook Complete.

Simpson, S. (2004). An XML representation for crew procedures technical report NASA faculty fellowship program (Johnson Space Center). https://ntrs.nasa.gov/api/citations/20050202022/downloads/20050202022.pdf

Van der Aalst, WMP. (1998). The application of Petri nets to workflow management. Journal of Circuits, Systems, and Computers, 8(1), 21-66.

White, S. A. (2004a). Business process modeling notation, v1.0. Technical report business process management initiative BPMI.

White, S. A. (2004b). Introduction to BPMN. Technical report, BP trends, IBM corporation.

Wohed, P., van der Aalst, W. M., Dumas, M., ter Hofstede, A. H., \& Russell, N. (2006). On the suitability of BPMN for business process modelling. In International Conference on Business Process Management (pp. 161-176). Springer.

Wu, X., Xiaoqiang, S., \& Zhang, L. (2019). The internet of things enabled shop floor scheduling and process control method based on petri nets. IEEE Access, 7, 27432-27442. 